\title{
Clinical implication of fasting glucose and systolic/diastolic blood pressure on the prevalence of periodontitis in non-diabetic and non-hypertensive adults using nationally representative data
}

\author{
KYUNGDO HAN ${ }^{1}$ and JUN-BEOM PARK ${ }^{2}$ \\ Departments of ${ }^{1}$ Biostatistics and ${ }^{2}$ Periodontics, College of Medicine, \\ The Catholic University of Korea, Seoul 06591, Republic of Korea
}

Received November 14, 2017; Accepted May 24, 2018

DOI: $10.3892 /$ etm.2018.6260

\begin{abstract}
The prevalence of diabetes mellitus and hypertension is increasing worldwide and an association between fasting glucose/blood pressure and periodontitis has been suggested. The present study was performed to assess the association between fasting glucose and systolic/diastolic blood pressure on the prevalence of periodontitis in non-diabetic and non-hypertensive adults using nationally representative data. Subgroup analysis was performed to evaluate the combined effects of obesity/abdominal obesity and impaired fasting glucose. This study involved a cross-sectional analysis using data from the Republic of Korean National Health and Nutrition Examination Survey from 2013 to 2015. A total of 8,341 respondents without diabetes and hypertension over 19 years old without missing values were included in the present study. A significant increase was observed in the prevalence of periodontitis with increasing systolic blood pressure and diastolic blood pressure. The percentage of periodontitis increased with increased glucose levels, with similar trends in glycated hemoglobin. The odds ratios (ORs) and $95 \%$ confidence intervals (CIs) for systolic blood pressure of $90 \leq x<100,100 \leq x<110,110 \leq x<120,120 \leq x<130$ and $130 \leq x<140$ were $1.116(0.591-2.107), 1.165(0.624-2.175), 1.238$ (0.673-2.278), 1.008 (0.538-1.888) and 1.042 (0.545-1.993), respectively, when systolic blood pressure $<90$ was considered as a reference. The ORs and $95 \%$ CIs for glucose of $90 \leq x<100$, $100 \leq x<110$ and $110 \leq x<126$ were $1.074(0.92-1.253), 1.214$ (0.986-1.494) and 1.358 (1.005-1.834), respectively when glucose $<90$ was considered as a reference. The association between fasting glucose/blood pressure and periodontitis was confirmed by multiple logistic regression analyses after
\end{abstract}

Correspondence to: Professor Jun-Beom Park, Department of Periodontics, College of Medicine, The Catholic University of Korea, 222 Banpo-daero, Seocho-gu, Seoul 06591, Republic of Korea

E-mail: jbassoonis@yahoo.co.kr

Key words: abdominal obesity, diabetes mellitus, health surveys, hypertension, obesity, periodontitis adjusting for confounding factors among non-diabetic and non-hypertensive Republic of Korean adults. Subgroup analysis revealed that higher ORs of periodontitis were observed in participants with impaired glucose level and obesity when compared with individuals without impaired glucose level or obesity. The results of the present study suggest that detection of fasting glucose and blood pressure may serve as a risk indicator for periodontal disease.

\section{Introduction}

Previous studies have shown that systemic diseases are known to be associated with periodontitis (1). The prevalence of both diabetes mellitus and hypertension is increasing worldwide (2). Diabetes and hypertension are widely studied for possible association with periodontitis $(3,4)$. The rapid increase in the prevalence of diabetes is also seen in Korea (5). The prevalence of diabetes among adults aged $\geq 30$ years in 2001, 2005 and 2007-2009 was 8.9, 9.1 and 9.9\%, respectively based on the series of Korea National Health and Nutrition Examination Surveys (5). The report with more current results showed that the prevalence of diabetes increased up to $11.0 \%$ in 2013 (6). Complication of diabetes includes diabetic retinopathy, diabetic nephropathy, diabetic neuropathy and macrovascular diseases (7). Previous report showed that the prevalence of hypertension was $28.5 \%$ in the Korean National Health and Nutrition Examination Survey in 2011 (8). The report indicated that the awareness, treatment, and control rates of the generation population were generally improved. Researchers have shown that a relationship exists between type 2 diabetes mellitus and periodontal disease (9). Glycemic control has been shown to affect periodontal disease and participants having poorly controlled diabetes were associated with severe periodontitis (10). Similarly, a positive association has been reported between hypertension and periodontitis (4). All periodontal measures had significant associations with hypertension (11).

However, the association between impaired fasting glucose or high blood pressure and periodontitis in individuals without diabetes or hypertension is not yet well understood. Thus, this study was performed to assess the relationship between fasting glucose and systolic/diastolic blood 
pressure on the prevalence of periodontitis in non-diabetic and non-hypertensive adults using nationally representative data. Subgroup analysis was performed to evaluate the combined effects of obesity/abdominal obesity and impaired fasting glucose.

\section{Materials and methods}

Survey and subjects. This survey was reviewed and approved by the Institutional Review Board of the Korean Centers for Disease Control and Prevention, and all participants provided written informed consent. This study is a secondary data analysis of data collected during the Korean National Health and Nutrition Examination Survey (KNHANES) from 2013 to 2015. The Institutional Review Board at the Catholic University of Korea approved of this study (KC16EISI0713). This study is a human observational study and the authors have conformed to the STROBE guidelines.

A total of 22,948 individuals participated in the KNHANES survey. The number of surveys was reduced to 13,401 by excluding participants without periodontal examination, participants with less than $8 \mathrm{~h}$ of fasting before examination, and individuals who were younger than 19 years old. The analysis in this study was confined to a total of 8,341 responses that had no missing values for the outcome variables (Fig. 1).

Demographic variables. Sociodemographic and lifestyle variables of participants were evaluated with a self-administered questionnaire regarding education level, household income, smoking, and alcohol intake. Smokers were classified as current smokers or non-smokers. Alcohol consumption was categorized as drinkers [mild to moderate drinkers (1-30 g/day)], and heavy drinkers (>30 g/day), or non-drinkers. Education level was categorized as either entered high school ( $\geq 10$ years) or not. Number of household members was evaluated. Household income was divided into quartiles by number of included family members. The lowest quartile of household income was less than 1,092.40 USD/month.

Anthropometric measurements. Trained staff members performed the measurements of the participants. Heath status of each participant was evaluated. Body weight and height were measured with the participants in light indoor clothing without shoes (12). Waist circumference was measured at the narrowest point between the lower border of the rib cage and the iliac crest. Body mass index was calculated by the following formula: weight $/$ height $^{2}\left(\mathrm{~kg} / \mathrm{m}^{2}\right)$. Systolic blood pressure and diastolic blood pressure were measured on the right arm using a standard mercury sphygmomanometer (Baumanometer; W.A. Baum Co., Inc., Copiague, NY, USA). Systolic blood pressure and diastolic blood pressure measurements were performed two times with a 5-min interval, and the average of the two measurements was used for the analysis.

After fasting for more than $8 \mathrm{~h}$, blood samples were collected from the antecubital veins. Serum fasting plasma glucose, glycated hemoglobin, the total concentration of cholesterol, low-density lipoprotein, and triglycerides were tested with the Automatic Analyzer 7600 (Hitachi, Tokyo, Japan ) using the kits (Daiichi, Tokyo, Japan ) (13).

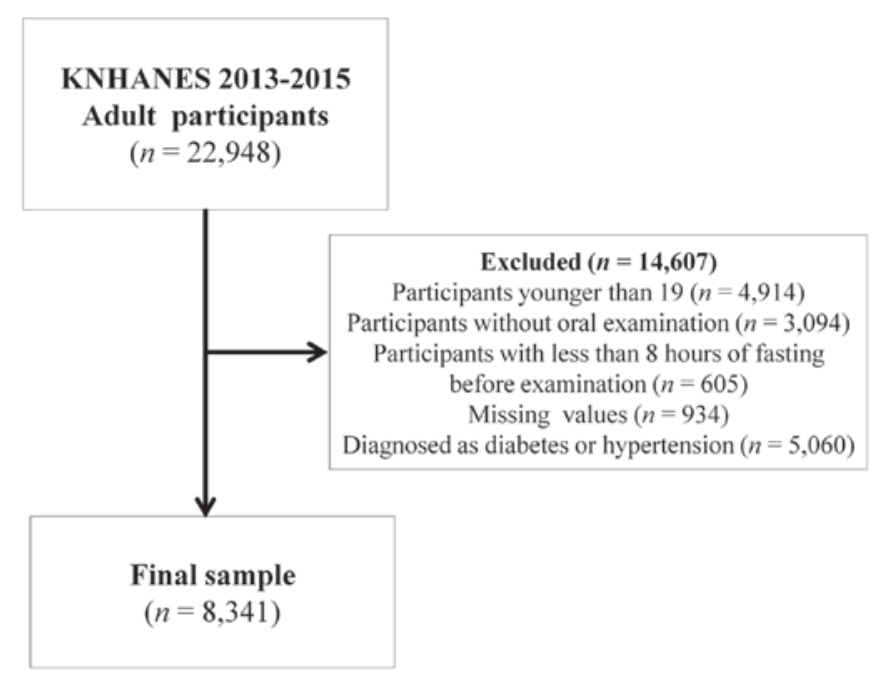

Figure 1. Participant flow chart.

Description of obesity, diabetes mellitus, and hypertension. Body mass index was categorized by $\geq 25 \mathrm{~kg} / \mathrm{m}^{2}$ or lower. Waist circumference was categorized as $\geq 90 \mathrm{~cm}$ in men and $\geq 80 \mathrm{~cm}$ in women. A body mass index $(\mathrm{BMI}) \geq 25 \mathrm{~kg} / \mathrm{m}^{2}$ was defined as the presence of obesity (14), and the cutoffs of abdominal obesity were defined as waist circumference (WC) $\geq 90 \mathrm{~cm}$ in men or $\geq 85 \mathrm{~cm}$ in women (15). Diabetes was diagnosed if fasting blood sugar was $\geq 126 \mathrm{mg} / \mathrm{dl}$, glycated hemoglobin was $\geq 6.5 \%$ or the individual was currently using antidiabetic medications (16). Impaired fasting glucose was defined as a level of blood glucose between 100 and $125 \mathrm{mg} / \mathrm{dl}$ with no diabetic medication. Hypertension was defined as systolic blood pressure $\geq 140 \mathrm{mmHg}$ and diastolic blood pressure was $\geq 90 \mathrm{mmHg}$ or reported use of regular antihypertensive drugs (17). Metabolic syndrome was diagnosed if three or more of the following criteria were fulfilled: waist circumference $\geq 90 \mathrm{~cm}$ in men and $\geq 80 \mathrm{~cm}$ in women; fasting triglycerides $\geq 150 \mathrm{mg} / \mathrm{dl}$ or use of lipid-lowering medication; high-density lipoprotein cholesterol $<40 \mathrm{mg} / \mathrm{dl}$ in men and $<50 \mathrm{mg} / \mathrm{dl}$ in women or use of lipid-lowering medication; blood pressure $\geq 130 / 85 \mathrm{mmHg}$ or use of antihypertensive medication; and fasting blood glucose $\geq 100 \mathrm{mg} / \mathrm{dl}$ or current use of antidiabetic medication (18).

Oral health behaviors and periodontitis. Periodontal treatment needs were assessed using the Community Periodontal Index (CPI), which the World Health Organization/Federation Dentaire Internationale has defined as an epidemiological screening procedure for rough depiction of periodontal status and treatment needs by trained dental practitioners (19). All teeth of each subject were divided into sextants. A specially designed periodontal probe (PWHO, Osung MND, Seoul, Republic of Korea) with a ball end $0.5 \mathrm{~mm}$ in diameter was used. Ten specific index teeth $(17,16,11,26,27,36,37,31$, 46 and 47) were examined to evaluate each sextant's score. A sextant was only scanned if two or more teeth were present. If index teeth were absent from a sextant, then all of the remaining teeth were examined to produce the score, and the highest score was recorded as the score for the sextant. Code 3 was used for a shallow pocket with depth of 3.5-5.5 mm and 
Table I. Baseline characteristics of study participants according to presence of periodontitis.

\begin{tabular}{|c|c|c|c|}
\hline \multirow[b]{2}{*}{ Variables } & \multicolumn{2}{|c|}{ Periodontitis } & \multirow[b]{2}{*}{ P-value ${ }^{a}$} \\
\hline & No & Yes & \\
\hline Total & 6,373 & 1,968 & \\
\hline Age, years & $37.94 \pm 0.23$ & $49.29 \pm 0.37$ & $<0.0001$ \\
\hline Male & $44.65(0.66)$ & $56.24(1.17)$ & $<0.0001$ \\
\hline Systolic blood pressure (mmHg) & $109.73 \pm 0.18$ & $112.91 \pm 0.31$ & $<0.0001$ \\
\hline Diastolic blood pressure (mmHg) & $72.33 \pm 0.15$ & $74.01 \pm 0.22$ & $<0.0001$ \\
\hline Glucose (mg/dl) & $91.66 \pm 0.15$ & $94.88 \pm 0.24$ & $<0.0001$ \\
\hline Glycated hemoglobin (\%) & $5.46 \pm 0.01$ & $5.59 \pm 0.01$ & $<0.0001$ \\
\hline Body mass index $\left(\mathrm{kg} / \mathrm{m}^{2}\right)$ & $22.98 \pm 0.05$ & $23.69 \pm 0.08$ & $<0.0001$ \\
\hline Body mass index $\geq 25 \mathrm{~kg} / \mathrm{m}^{2}(\%)$ & $23.64(0.62)$ & $30.92(1.20)$ & $<0.0001$ \\
\hline Waist circumference $(\mathrm{cm})$ & $78.33 \pm 0.17$ & $81.4 \pm 0.24$ & $<0.0001$ \\
\hline Waist circumference $\geq 90 \mathrm{~cm}$ in men and $\geq 80 \mathrm{~cm}$ in women $(\%)$ & $15.37(0.56)$ & $21.6(1.11)$ & $<0.0001$ \\
\hline Metabolic syndrome (yes) & $9.6(0.43)$ & $18.76(1.08)$ & $<0.0001$ \\
\hline Total cholesterol (mg/dl) & $184.57 \pm 0.50$ & $193.38 \pm 0.88$ & $<0.0001$ \\
\hline Low-density lipoprotein (mg/dl) & $109.12 \pm 0.43$ & $116.9 \pm 0.81$ & $<0.0001$ \\
\hline Triglycerides $^{\mathrm{b}}$ & $95.07(93.48-96.69)$ & $116.28(112.80-119.88)$ & $<0.0001$ \\
\hline Smoking, current & $16.39(0.66)$ & $27.52(1.33)$ & $<0.0001$ \\
\hline Drinking, current & $61.74(0.70)$ & $58.78(1.37)$ & 0.0421 \\
\hline Education-university graduate or higher & $45.47(0.90)$ & $32.61(1.51)$ & $<0.0001$ \\
\hline Income, lowest quartile & $9.14(0.54)$ & $12.52(0.96)$ & 0.0004 \\
\hline Number of natural teeth & $26.6 \pm 0.05$ & $24.94 \pm 0.13$ & $<0.0001$ \\
\hline Frequency of tooth brushing per day & & & $<0.0001$ \\
\hline$\leq 1$ & $6.55(0.37)$ & $9.98(0.78)$ & \\
\hline 2 & $34.09(0.66)$ & $39.94(1.36)$ & \\
\hline$\geq 3$ & $59.36(0.72)$ & $50.08(1.38)$ & \\
\hline Use of secondary oral products & $56.99(0.77)$ & $52.18(1.43)$ & 0.0021 \\
\hline Tooth pain & $35.99(0.87)$ & $44.89(1.41)$ & $<0.0001$ \\
\hline
\end{tabular}

Data are presented as mean \pm standard error of the mean or percentages (standard error). ${ }^{\text {a }}$-values were obtained by independent $\mathrm{t}$-test for continuous variables or Chi-square test for categorical variables. ${ }^{\mathrm{b}} \mathrm{Geometric}$ mean (95\% confidence of intervals).

code 4 for a deep pocket depth $\geq 5.5 \mathrm{~mm}$. Moderate periodontal disease was defined if CPI was code 3 and severe periodontitis was defined if CPI was code 4 . Presence of periodontitis was defined if CPI was 3 or greater.

The frequency of daily tooth brushing and use of secondary oral products were used for the evaluation of oral health behavior. Secondary oral products included dental floss, mouthwash, interdental brushes, electric toothbrushes, irrigation devices, tongue cleaners, end-tufted brushes, and special devices for dentures. The survey also recorded the participants' tooth pain.

Statistical analysis. All analyses were conducted using SAS version 9.3 (SAS Institute Inc., Cary, NC, USA). The SAS survey procedure was applied to reflect the complex sampling design and the sampling weights of KNHANES and to provide nationally representative prevalence estimates. The data are presented as the mean \pm standard error of the mean for continuous variables and as proportions (standard errors) for categorical variables. A Chi-square test for categorical variables or an independent t-test for continuous variables was performed to assess the differences in characteristics categorized by presence of periodontitis. Logistic regression analysis was used to evaluate the periodontitis in association with impaired fasting glucose categorized by the presence of obesity or abdominal obesity. The model was adjusted for age, sex, smoking, drinking, education, income, body mass index, number of natural teeth, frequency of tooth brushing per day, and use of secondary oral products.

\section{Results}

Table I shows the baseline characteristics of study participants according to the presence of periodontitis. Among the 8,341 participants, 1,968 were diagnosed as having periodontitis. The percentage of males was higher in periodontitis group $(\mathrm{P}<0.05)$. The systolic blood pressure, diastolic blood pressure, glucose level, glycated hemoglobin, body mass index, total cholesterol, low-density lipoprotein, and triglycerides were statistically higher in the periodontitis group $(\mathrm{P}<0.05)$. 


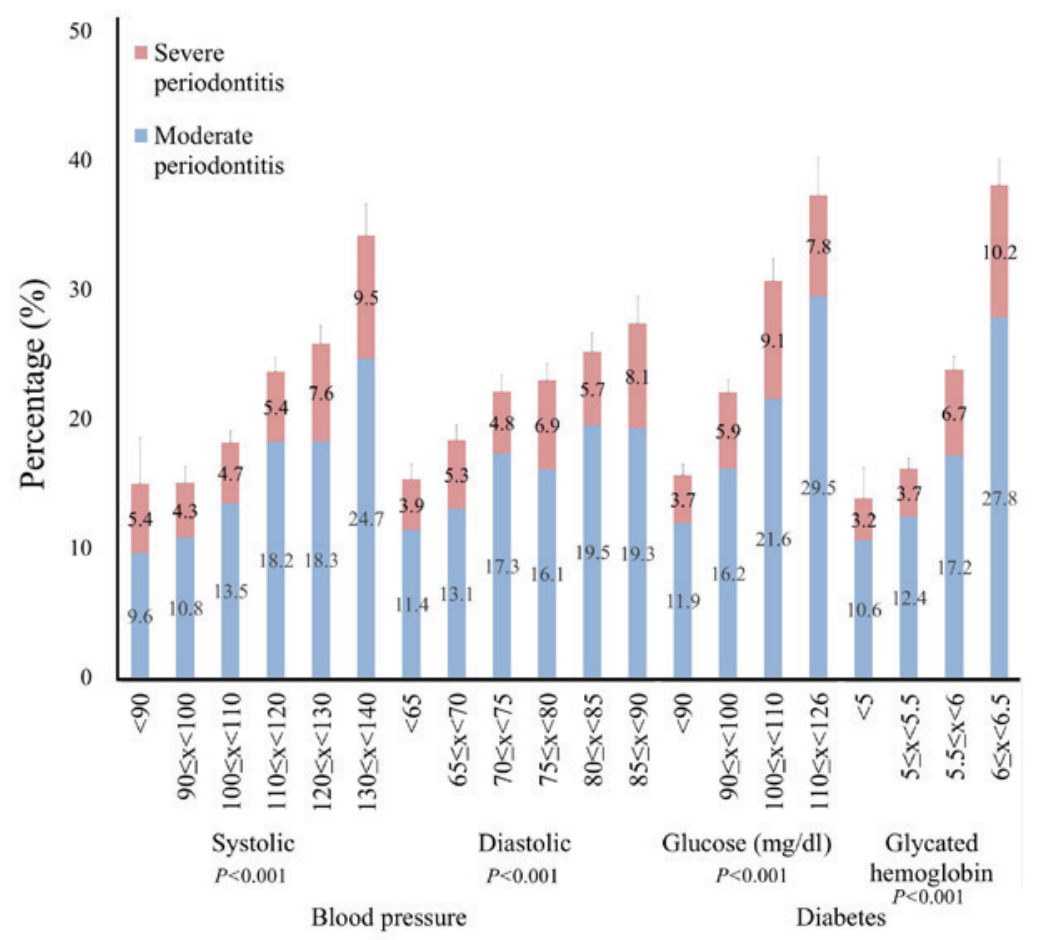

Figure 2. Percentage of moderate and severe periodontitis as categorized by blood pressure and glucose level.
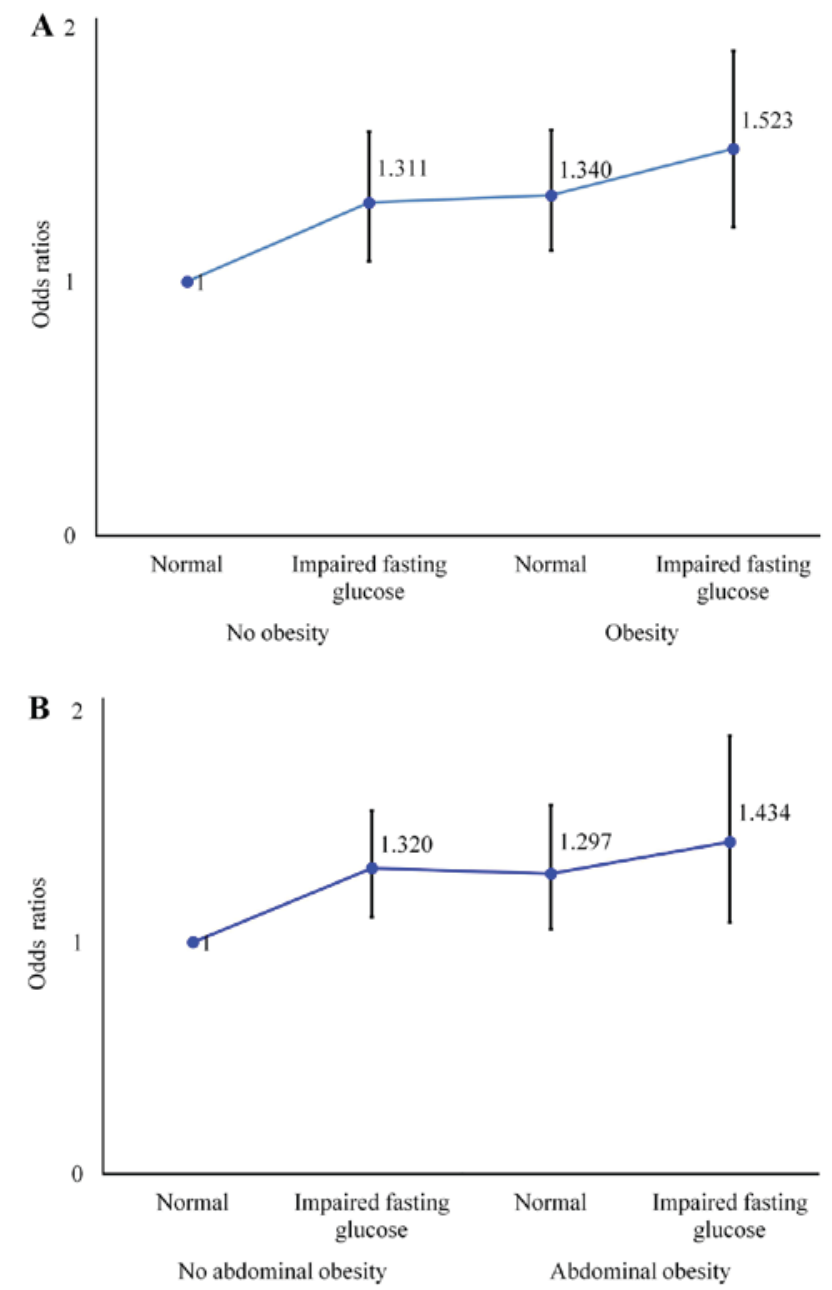

Figure 3. Odds ratios of periodontitis categorized by the (A) presence of obesity and impaired fasting glucose or (B) the presence of abdominal obesity and impaired fasting glucose.
The numbers of current smokers and individuals with lower income or tooth pain were higher in the periodontitis group. However, the percentage of individuals with tooth brushing frequency of three or higher per day and the percentage of individuals using secondary oral products were significantly lower in the periodontitis group $(\mathrm{P}<0.05)$.

The percentage of moderate and severe periodontitis categorized by blood pressure and glucose level is shown in Fig. 2. The percentage of periodontitis increased with increasing systolic blood pressure. Similar trends were seen with diastolic blood pressure. The percentage of periodontitis increased with higher glucose level, with similar trends in glycated hemoglobin.

The prevalence of periodontitis in the combination of obesity/abdominal obesity and impaired fasting glucose level is shown in Fig. 3. Fig. 3A shows odds ratios (ORs) of periodontitis categorized by the presence of obesity and impaired fasting glucose. Even for participants without obesity, the ORs increased to 1.311. For participants with obesity having impaired fasting glucose, the ORs of periodontitis increased to 1.523. Similar trends were seen with participants with abdominal obesity (Fig. 3B). ORs for participants without abdominal obesity having impaired glucose, participants with abdominal obesity with normal glucose level, and individuals having combination of abdominal obesity and impaired fasting glucose were $1.320,1.297$ and 1.434, respectively, when a non-abdominally obese individual with normal fasting glucose was considered as reference.

Fig. 4 shows ORs and 95\% confidence intervals (CIs) of periodontitis after adjustments for age, sex, smoking, drinking, education, income, body mass index, waist circumference, chronic kidney disease, number of natural teeth, frequency of tooth brushing per day, and use of secondary oral products.

Table II shows the ORs and 95\% CIs of periodontitis categorized by systolic blood pressure, diastolic blood pressure, 


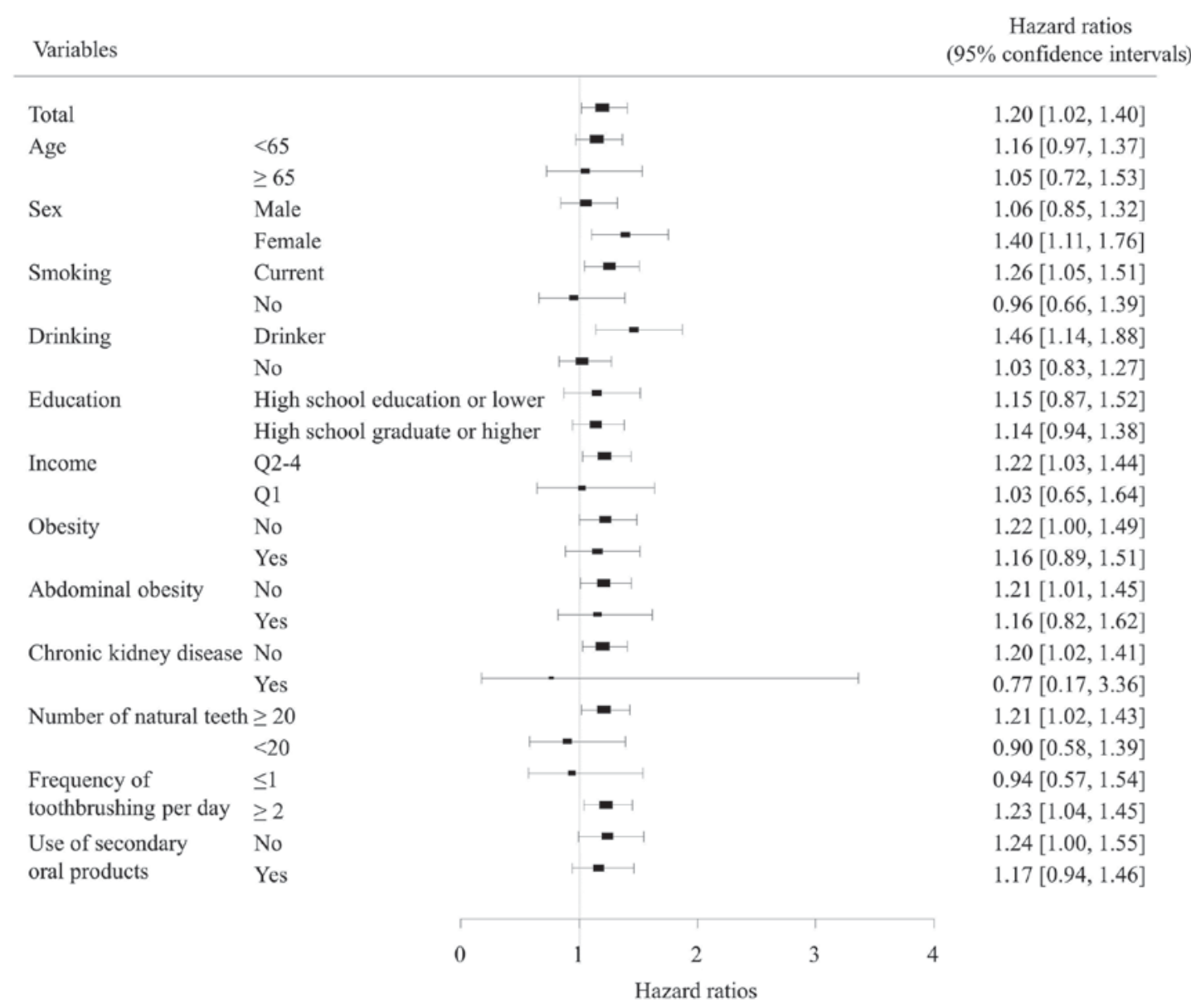

Figure 4. Hazard ratios and 95\% confidence intervals of periodontitis in individuals with impaired fasting glucose after adjustments for age, sex, smoking, drinking, education, income, body mass index, waist circumference, chronic kidney disease, number of natural teeth, frequency of tooth brushing per day, use of secondary oral products and duration of sleep.

glucose, and glycated hemoglobin. The ORs and 95\% CIs for systolic blood pressure of $90 \leq x<100,100 \leq x<110,110 \leq x<120$, $120 \leq x<130$, and $130 \leq x<140$ were $1.116(0.591,2.107), 1.165$ $(0.624,2.175), 1.238(0.673,2.278), 1.008(0.538,1.888)$, and $1.042(0.545,1.993)$, respectively, when systolic blood pressure $<90$ was considered as reference. The ORs and 95\% CIs for diastolic blood pressure of $65 \leq x<70,70 \leq x<75,75 \leq x<80$, $80 \leq x<85$, and $85 \leq x<90$ were $1.192(0.94,1.511), 1.324(1.049$, $1.67), 1.152(0.905,1.467), 1.188(0.931,1.516)$, and 1.263 (0.937, 1.702), respectively, when diastolic blood pressure $<65$ was considered as reference. The ORs and 95\% CIs for glucose of $90 \leq x<100,100 \leq x<110$, and $110 \leq x<126$ were 1.074 (0.92, 1.253), $1.214(0.986,1.494)$, and 1.358 (1.005, 1.834), respectively, when glucose $<90$ was considered as reference. The ORs and 95\% CIs for glycated hemoglobin $5 \leq x<5.5$, $5.5 \leq x<6$, and $6 \leq x<6.5$ were $0.887(0.583,1.348), 0.853(0.559$, $1.301)$, and $1.021(0.652,1.599)$, respectively, when glycated hemoglobin $<5$ was considered as reference.

\section{Discussion}

This study showed that both impaired fasting glucose and prehypertension were associated with periodontitis by multiple logistic regression analyses after adjusting for confounding factors among Korean adults. Subgroup analysis revealed that ORs of periodontitis increased in impaired fasting glucose in both non-obese and obese participants. Highest ORs were seen with the combination of impaired fasting glucose and obesity/abdominal obesity.

Various parameters can be used to determine impaired fasting glucose and prehypertension (17,20-24). Impaired fasting glucose was defined as a level of blood glucose between 100 and $125 \mathrm{mg} / \mathrm{dl}$ with no diabetic medication (17). The criteria for the World Health Organization is $110 \leq \mathrm{x}<125 \mathrm{mg} / \mathrm{dl}(20)$. Regarding hypertension, if the participants were $\geq 60$ years old, then average blood pressure of 150/90 mmHg or lower was considered as controlled, and the criteria of blood pressure $<140 / 90 \mathrm{mmHg}$ was considered controlled for individuals younger than 60 (21). A previous report recommended lower targets for individuals with diabetes mellitus of $130 / 80 \mathrm{mmHg}$ (22). In a previous study, prehypertension was defined as systolic blood pressure between 120 and $139 \mathrm{mmHg}$ or diastolic blood pressure between 80 to $89 \mathrm{mmHg}$ (23). In another study, participants with repeated measurements of systolic pressure of 130 to $139 \mathrm{mmHg}$ and diastolic pressure of $89 \mathrm{mmHg}$ or lower, or systolic pressure of $139 \mathrm{mmHg}$ or lower and diastolic pressure of 85 to $89 \mathrm{mmHg}$, were assigned to the treatment of prehypertension (24). In this study, we classified the glucose level and glycated hemoglobin into four stages according to the severity. Systolic and diastolic blood pressure was categorized into six stages according to the severity. 
Table II. Odds ratios and 95\% confidence interval for periodontitis categorized by systolic blood pressure, diastolic blood pressure, glucose and glycated hemoglobin.

Odds ratios (95\% confidence interval)

\begin{tabular}{|c|c|c|c|}
\hline \multirow{2}{*}{ Variables } & & & \\
\hline & Model 1 & Model 2 & Model 3 \\
\hline \multicolumn{4}{|c|}{ Systolic blood pressure $(\mathrm{mmHg})$} \\
\hline$<90$ & 1 (reference) & 1 (reference) & 1 (reference) \\
\hline $90 \leq x<100$ & $1.191(0.642,2.21)$ & $1.113(0.589,2.101)$ & $1.118(0.591,2.114)$ \\
\hline $100 \leq x<110$ & $1.247(0.676,2.301)$ & $1.156(0.619,2.158)$ & $1.169(0.625,2.185)$ \\
\hline $110 \leq x<120$ & $1.37(0.754,2.487)$ & $1.243(0.676,2.284)$ & $1.245(0.676,2.293)$ \\
\hline $120 \leq x<130$ & $1.183(0.641,2.184)$ & $1.014(0.542,1.899)$ & $1.013(0.540,1.900)$ \\
\hline $130 \leq x<140$ & $1.259(0.669,2.369)$ & $1.072(0.56,2.055)$ & $1.044(0.545,2.002)$ \\
\hline \multicolumn{4}{|c|}{ Diastolic blood pressure $(\mathrm{mmHg})$} \\
\hline$<65$ & 1 (reference) & 1 (reference) & 1 (reference) \\
\hline $65 \leq x<70$ & $1.149(0.912,1.447)$ & $1.171(0.927,1.481)$ & $1.193(0.941,1.513)$ \\
\hline $70 \leq x<75$ & $1.391(1.107,1.747)$ & $1.322(1.05,1.665)$ & $1.325(1.050,1.672)$ \\
\hline $75 \leq x<80$ & $1.227(0.968,1.556)$ & $1.156(0.91,1.468)$ & $1.156(0.908,1.472)$ \\
\hline $80 \leq x<85$ & $1.267(0.995,1.612)$ & $1.177(0.924,1.498)$ & $1.190(0.933,1.519)$ \\
\hline $85 \leq x<90$ & $1.443(1.082,1.925)$ & $1.271(0.945,1.711)$ & $1.270(0.942,1.711)$ \\
\hline \multicolumn{4}{|c|}{ Glucose $(\mathrm{mg} / \mathrm{dl})$} \\
\hline$<90$ & 1 (reference) & 1 (reference) & 1 (reference) \\
\hline $90 \leq x<100$ & $1.113(0.959,1.292)$ & $1.076(0.923,1.254)$ & $1.071(0.918,1.250)$ \\
\hline $100 \leq x<110$ & $1.333(1.093,1.627)$ & $1.214(0.988,1.492)$ & $1.212(0.984,1.492)$ \\
\hline $110 \leq x<126$ & $1.542(1.163,2.044)$ & $1.364(1.014,1.835)$ & $1.355(1.003,1.830)$ \\
\hline \multicolumn{4}{|c|}{ Glycated hemoglobin (\%) } \\
\hline$<5$ & 1 (reference) & 1 (reference) & 1 (reference) \\
\hline $5 \leq x<5.5$ & $0.958(0.634,1.447)$ & $0.893(0.586,1.36)$ & $0.887(0.584,1.349)$ \\
\hline $5.5 \leq x<6$ & $1.027(0.68,1.55)$ & $0.864(0.565,1.321)$ & $0.853(0.559,1.302)$ \\
\hline $6 \leq x<6.5$ & $1.354(0.881,2.081)$ & $1.072(0.682,1.684)$ & $1.018(0.650,1.594)$ \\
\hline
\end{tabular}

Model 1, Age and sex adjusted; Model 2, Model 1 + smoking, drinking, education, income, and body mass index adjusted; Model 3 , Model $2+$ number of natural teeth, frequency of tooth brushing per day, use of secondary oral products and duration of sleep adjusted.

A previous report recommended initiating treatment in adults aged 60 years or older with systolic blood pressure persistently at or above $150 \mathrm{mmHg}$ to achieve a target systolic blood pressure of less than $150 \mathrm{mmHg}$ to reduce the risk for mortality, stroke, and cardiac events (25). However, it was noted that evidence was low in quality for achieving a target systolic blood pressure of less than $140 \mathrm{mmHg}$ to reduce the risk of stroke or cardiac events. Similarly, another report showed that more intensive blood pressure-lowering treatment of a group with mean blood pressure level of $133 / 76 \mathrm{mmHg}$ resulted in no clear effects on total mortality, cardiovascular death, heart failure, or end-stage renal disease (26). Fewer studies have been performed regarding prehypertension and it was shown that prehypertension was considered a precursor of stage 1 hypertension and a predictor of excessive cardiovascular risk (24). Prevalence of periodontitis in the prehypertension group increased from $25.8 \%$ for systolic blood pressure of $120 \leq x<130 \mathrm{mmHg}$ and $34.2 \%$ for $130 \leq x<140 \mathrm{mmHg}$, respectively. Prevalence of periodontitis in the prehypertension group increased from 25.2 to $27.4 \%$ for diastolic blood pressure of $80 \leq x<85$ and $85 \leq x<90 \mathrm{mmHg}$, respectively.
A previous report showed pre-diabetes related to impaired fasting glucose was positively associated with periodontitis (27). Research has also shown that periodontitis showed an association with decreased $\beta$-cell function and increased prevalence of impaired fasting glucose before onset of diabetes (28). It was also shown that chronic periodontitis measured by clinical attachment loss and pocket depth was positively associated in a linear relation with impaired fasting glucose (28). This study also showed that the percentage of periodontitis increased from $22.0 \%$ for fasting glucose level of $90 \leq x<100 \mathrm{mg} / \mathrm{dl}, 30.7 \%$ for fasting glucose level of $100 \leq x<110 \mathrm{mg} / \mathrm{dl}$, and $37.3 \%$ for fasting glucose level of $110 \leq x<126 \mathrm{mg} / \mathrm{dl}$. ORs of periodontitis increased with impaired fasting glucose and combination of obesity and impaired fasting glucose showed the highest ORs of 1.523 . The relative increase of ORs of impaired fasting glucose for periodontitis was 1.311 for no obesity but 1.137 for the obesity group. Similar trends were seen regarding abdominal obesity. The relative increase of ORs of impaired fasting glucose for periodontitis was 1.320 for no abdominal obesity but 1.106 for the abdominal obesity group. It should also be considered that 
more care may be given to prehypertensive individuals with impaired fasting glucose (23).

This study emphasized the importance of evaluation and treatment of periodontitis in individuals with prediabetes and prehypertension. This study has great strength because the conclusion was derived from nationally representative data (29). The design of this study is based on a stratified, multistage, probability-cluster survey of the population of institutionalized civilians (30). Oral health was evaluated using periodontal index from index teeth using probing depth (31). A multiple regression analysis was used to evaluate periodontitis in relation to impaired fasting glucose and blood pressure after adjustment for various confounding factors including age, sex, smoking, drinking, socioeconomic factors, oral health behavior, and systemic diseases (32). However, it should be noted that the causal direction of the associations between prediabetes/prehypertension and periodontitis cannot be ascertained due to the design of this study being cross-sectional (33).

The association between fasting glucose/blood pressure and periodontitis was proven by multiple logistic regression analyses after adjusting for confounding factors among non-diabetic and non-hypertensive Korean adults. Subgroup analysis showed that higher ORs of periodontitis were noted in participants having both impaired glucose level and obesity when compared with individuals without impaired glucose level or obesity. Further prospective studies with a larger sample size of individuals over a longer period of time are required to evaluate the cause-and-effect association. The results of the present study suggest that detection of fasting glucose and blood pressure may serve as a risk indicator for periodontal disease.

\section{Acknowledgements}

The authors thank the Korea Centers for Disease Control and Prevention for providing the necessary data.

\section{Funding}

This study was supported by Research Fund of Seoul St. Mary's Hospital, The Catholic University of Korea. This work was partly supported by Basic Science Research Program through the National Research Foundation of Korea funded by the Ministry of Science, ICT \& Future Planning, Daejeon, Republic of Korea (grant no. NRF-2017R1A1A1A05001307).

\section{Availability of data and materials}

All data generated or analyzed during this study are included in this published article.

\section{Authors' contributions}

$\mathrm{KH}$ and JP collaborated to design the study; KH and JP were responsible for data access and analysis; $\mathrm{KH}$ and JP wrote the manuscript; both authors reviewed the manuscript.

\section{Ethics approval and consent to participate}

The Institutional Review Board at the Catholic University of Korea approved this study (approval no. KC16EISI0713).

\section{Patient consent for publication}

Not applicable.

\section{Competing interests}

The authors confirm that they have no competing interests.

\section{References}

1. Kim J and Amar S: Periodontal disease and systemic conditions: A bidirectional relationship. Odontology 94: 10-21, 2006.

2. Tatsumi Y and Ohkubo T: Hypertension with diabetes mellitus: Significance from an epidemiological perspective for Japanese. Hypertens Res 40: 795-806, 2017.

3. Macedo Paizan ML and Vilela-Martin JF: Is there an association between periodontitis and hypertension? Curr Cardiol Rev 10: 355-361, 2014.

4. Choi HM, Han K, Park YG and Park JB: Associations among oral hygiene behavior and hypertension prevalence and control: The 2008 to 2010 Korea national health and nutrition examination survey. J Periodontol 86: 866-873, 2015.

5. Cho NH: Diabetes burden and prevention in Korea and the Western Pacific Region. Diabetes Res Clin Pract 106 (Suppl 2): S282-S287, 2014.

6. Ha KH and Kim DJ: Current status of managing diabetes mellitus in Korea. Korean J Intern Med 31: 845-850, 2016.

7. Cade WT: Diabetes-related microvascular and macrovascular diseases in the physical therapy setting. Phys Ther 88: 1322-1335, 2008.

8. Lee HY and Park JB: The Korean society of hypertension guidelines for the management of hypertension in 2013: Its essentials and key points. Pulse (Basel) 3: 21-28, 2015.

9. Amiri AA, Maboudi A, Bahar A, Farokhfar A, Daneshvar F, Khoshgoeian HR, Nasohi M and Khalilian A: Relationship between Type 2 diabetic retinopathy and periodontal disease in iranian adults. N Am J Med Sci 6: 139-144, 2014.

10. Lakschevitz F, Aboodi G, Tenenbaum H and Glogauer M: Diabetes and periodontal diseases: Interplay and links. Curr Diabetes Rev 7: 433-439, 2011.

11. Tsakos G, Sabbah W, Hingorani AD, Netuveli G, Donos N, Watt RG and D'Aiuto F: Is periodontal inflammation associated with raised blood pressure? Evidence from a National US survey. J Hypertens 28: 2386-2393, 2010.

12. Nam GE, Kim do H, Cho KH, Park YG, Han KD, Choi YS, Kim SM, Ko BJ, Kim YH and Lee KS: Estimate of a predictive cut-off value for serum 25-hydroxyvitamin D reflecting abdominal obesity in Korean adolescents. Nutr Res 32: 395-402, 2012.

13. Wallace TM, Levy JC and Matthews DR: Use and abuse of HOMA modeling. Diabetes Care 27: 1487-1495, 2004.

14. Oh SW, Shin SA, Yun YH, Yoo T and Huh BY: Cut-off point of BMI and obesity-related comorbidities and mortality in middle-aged Koreans. Obes Res 12: 2031-2040, 2004.

15. Lee S, Park HS, Kim SM, Kwon HS, Kim DY, Kim DJ, Cho GJ, Han JH, Kim SR, Park CY, et al: Cut-off points of waist circumference for defining abdominal obesity in the Korean population. Korean J Obes 15: 1-9, 2006.

16. Jeon JY, Ko SH, Kwon HS, Kim NH, Kim JH, Kim CS, Song KH, Won JC, Lim S, Choi SH, et al: Prevalence of diabetes and prediabetes according to fasting plasma glucose and HbAlc. Diabetes Metab J 37: 349-357, 2013.

17. Worede A, Alemu S, Gelaw YA and Abebe M: The prevalence of impaired fasting glucose and undiagnosed diabetes mellitus and associated risk factors among adults living in a rural Koladiba town, northwest Ethiopia. BMC Res Notes 10: 251, 2017.

18. Kim YH, Kim DH, Lim KS, Ko BJ, Han BD, Nam GE, Park YG, Han KD, Kim JH andCho KH: Oral health behaviors and metabolic syndrome: The 2008-2010 Korean National Health And Nutrition Examination Survey. Clin Oral Investig 18: 1517-1524, 2014.

19. Park JB, Han K, Park YG and Ko Y: Association between alcohol consumption and periodontal disease: The 2008 to 2010 Korea national health and nutrition examination survey. J Periodontol 85: 1521-1528, 2014.

20. Alberti KG and Zimmet PZ: Definition, diagnosis and classification of diabetes mellitus and its complications. Part 1: diagnosis and classification of diabetes mellitus provisional report of a WHO consultation. Diabet Med 15: 539-553, 1998. 
21. James PA, Oparil S, Carter BL, Cushman WC, Dennison-Himmelfarb C, Handler J, Lackland DT, LeFevre ML, MacKenzie TD, Ogedegbe O, et al: 2014 evidence-based guideline for the management of high blood pressure in adults: Report from the panel members appointed to the Eighth Joint National Committee (JNC 8). JAMA 311: 507-520, 2014.

22. Arguedas JA, Leiva V and Wright JM: Blood pressure targets for hypertension in people with diabetes mellitus. Cochrane Database Syst Rev CD008277, 2013.

23. Zhang Y, Lee ET, Devereux RB, Yeh J, Best LG, Fabsitz RR and Howard BV: Prehypertension, diabetes, and cardiovascular disease risk in a population-based sample: The Strong Heart Study. Hypertension 47: 410-414, 2006.

24. Julius S, Nesbitt SD, Egan BM, Weber MA, Michelson EL, Kaciroti N, Black HR, Grimm RH Jr, Messerli FH, Oparil S, et al: Feasibility of treating prehypertension with an angiotensin-receptor blocker. N Engl J Med 354: 1685-1697, 2006.

25. Qaseem A, Wilt TJ, Rich R, Humphrey LL, Frost J and Forciea MA; Clinical Guidelines Committee of the American College of Physicians and the Commission on Health of the Public and Science of the American Academy of Family Physician: Pharmacologic treatment of hypertension in adults aged 60 years or older to higher versus lower blood pressure targets: A clinical practice guideline from the american college of physicians and the american academy of family physicians. Ann Intern Med 166: 430-437, 2017.

26. Xie X, Atkins E, Lv J, Bennett A, Neal B, Ninomiya T, Woodward M, MacMahon S, Turnbull F, Hillis GS, et al: Effects of intensive blood pressure lowering on cardiovascular and renal outcomes: Updated systematic review and meta-analysis. Lancet 387: 435-443, 2016.

27. Arora N, Papapanou PN, Rosenbaum M, Jacobs DR Jr, Desvarieux M and Demmer RT: Periodontal infection, impaired fasting glucose and impaired glucose tolerance: Results from the continuous national health and nutrition examination survey 2009-2010. J Clin Periodontol 41: 643-652, 2014.
28. Islam SK, Seo M, Lee YS and Moon SS: Association of periodontitis with insulin resistance, beta-cell function and impaired fasting glucose before onset of diabetes. Endocr J 62: 981-989, 2015.

29. Song IS, Han K, Ryu JJ and Park JB: Association between underweight and tooth loss among Korean adults. Sci Rep 7: 41524, 2017.

30. Hong M, Park JB, Kim YS, Lee DH, Kim H, Lee JI, Ahn HS, Sohn TS, Lee TK, et al: Association between Cockroach-specific Immunoglobulin $\mathrm{E}$ and periodontitis in Korean male adults Based on Korean National Health And Nutrition Examination Survey. Sci Rep 7: 46373, 2017.

31. Han K, Ko Y, Park YG and Park JB: Associations between the periodontal disease in women before menopause and menstrual cycle irregularity: The 2010-2012 Korea national health and nutrition examination survey. Medicine (Baltimore) 95: e2791, 2016.

32. Choi HM, Han K, Park YG and Park JB: Associations between the number of natural teeth and renal dysfunction. Medicine (Baltimore) 95: e4681, 2016.

33. Han K and Park JB: Association between oral health behavior and periodontal disease among Korean adults: The Korea national health and nutrition examination survey. Medicine (Baltimore) 96: e6176, 2017.

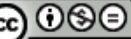

This work is licensed under a Creative Commons
Attribution-NonCommercial-NoDerivatives 4.0 International (CC BY-NC-ND 4.0) License. 